\title{
Experimental Investigation of Flow Structures around a Torpedo-like Geometry Placed in a Boundary Layer Flow
}

\author{
M. A. H. Hayder ${ }^{1, *}$, I. Goktepeli ${ }^{1}$, S. Yagmur ${ }^{1}$, M. Ozgoren ${ }^{1}$, F. Kose ${ }^{1}$, L. A. Kavurmacioglu ${ }^{2}$ \\ ${ }^{1}$ Department of Mechanical Engineering, Selcuk University, Turkey \\ ${ }^{2}$ Department of Mechanical Engineering, Istanbul Technical University, Turkey
}

Copyright $\bigcirc 2018$ by authors, all rights reserved. Authors agree that this article remains permanently open access under the terms of the Creative Commons Attribution License 4.0 International License

\begin{abstract}
Defense applications for both under oceans and seas, particularly underwater vehicles have been considered in this research. With this aim, flow characteristics around a torpedo-like geometry under the effect of the boundary layer flow over a smooth flat plate have been experimentally examined by using PIV technique. All of the experiments have been done for $R e=20000$ and $R e=40000$ based on the length (L) of the geometry as a characteristic length. As a result, time-averaged streamwise velocity components $\left\langle\mathrm{u}^{*}\right\rangle$, velocity vectors $\langle\mathrm{v}\rangle$, streamline topologies $\langle\psi\rangle$ and Reynolds stress correlations $\left\langle\mathrm{u}^{\prime} \mathrm{v}^{\prime} / \mathrm{U}_{\infty}{ }^{2}\right\rangle$ in the wake region of the torpedo-like geometry have been acquired in the range of $0 \leq \mathrm{G} / \mathrm{D} \leq 1.5$. Here, $\mathrm{G}$ is the space between the bottom point of the geometry and flat plate surface; D stands for the diameter of the geometry. It is found that at the smallest value of $\mathrm{G} / \mathrm{D}=0.25$, jet-like flow occurs between the plate and the model which causes a powerful scouring. As the gap ratio is increased to $G / D=0.5$ and $\mathrm{G} / \mathrm{D}=1.0$, the jet-like flow diminishes slightly and then the flow structure in the wake region becomes similar to the uniform incoming flow condition for $\mathrm{G} / \mathrm{D}=1.50$. Due to the effect of the jet-like flow and boundary layer flow, time-averaged flow patterns present asymmetrical distributions which are clearly shown a bigger size focus close to the plate in streamline topology. Reynolds stress patterns form more powerful viscous forces in the boundary layer flow due to the occurrence of eddy vortices and viscosity effect. It is observed from the aforementioned flow patterns that interaction between the flow structure, the model and boundary layer flow yields very complex structure. In order to decrease the energetic flow in this condition, passive or active flow control method can be integrated on the torpedo-like geometry.
\end{abstract}

Keywords Boundary Layer Flow, PIV, Turbulent Flow, Torpedo-like Geometry, Vorticity

\section{Introduction}

Torpedoes, torpedo-like geometries and underwater unmanned vehicles have been investigated in this research. Even though seas and oceans cover two-thirds of the earth, interests in oceans and seas are not enough when compared to land and atmosphere. A number of researches have been deduced to study the flow around underwater vehicles. These bodies are representative of natural and engineered objects such as torpedoes that swim like tuna. It is known from the researches underwater vehicles exposed to more viscous and hydrostatic forces than air and land for same geometry. In the literature, a lot of studies can be encountered about the flow around underwater vehicles. Zhao et al. (2016) investigated the vortex dynamics characteristics and wake structure of a sphere close to the wall at the Reynolds number $R e=4170$. The results of sphere situated near to flat plate were straightly founded by numerical simulations. They found the increase in boundary layer of sphere, in addition the effect of $g / d$ on the velocity distributions as the gap ratios increase the velocity interaction because of its weakness. Ozgoren et al. (2013) investigated flow patterns around sphere placed over flat plate by using PIV and dye visualization. The closer position of the sphere to the wall result in distribution of Reynolds stress correlations $\left(u^{\prime} v^{\prime} / U_{\infty}{ }^{2}\right)$. They found the boundary layer thickness about $63 \mathrm{~mm}$ and observed flow characteristics around sphere at different gap ratios with flat plate for $0 \leq \mathrm{G} / \mathrm{D} \leq 1.5$ at $2500 \leq \mathrm{Re} \leq$ 10000 in terms of the turbulent boundary layer generated by using trip wire. Nian-Sheng Cheng (2007) obtained analytically that the power law can be obtained as the first order approximation to the log law, it was found that power law index was calculated with the dependence on Reynolds number alongside relative roughness height and the highest power index are required for flow upon very rough boundaries. Ozalp and Dincer (2010) studied extensively computational analysis on the hydrodynamics, thermal, and mass transfer attribution of a circular cylinder, depend 
on the flow structure at $\mathrm{Re}=40$. The results were specified at the higher blockage and the highest blockage of $\beta=0.8$ was used to simulate the downstream velocity values and the boundary layer distributed by the fluid-solid contact. Ozgoren et al. (2011) have compared the flow structures in the wake region of both a cylinder and a sphere. They have done experiments of immersed bodies which were in the free-stream flow for $\mathrm{Re}=5000$ and $\mathrm{Re}=10000$ and they have used PIV and dye techniques. They have obtained Strouhal number values for a cylinder as $\mathrm{St}=0.21$ and a sphere as $\mathrm{St}=0.18$ at $\mathrm{Re}=5000$, respectively. Lin et al. (2016) investigated experimentally the characteristics of horizontal velocity profiles in the bottom boundary-layer flow. Here, the results were obtained by using High-Speed Particle Image Velocimetry (HSPIV) method. The experiments were done at different the ratio of wave height to water depth varying from 0.096 to 0.386 for the boundary layer in terms of laminar flow. They investigated the time influence on the horizontal velocity profile distributions. They obtained that the velocity profiles were divided into two parts depending on solitary wave-crest at measuring; when favorable pressure exerted the pre-passing (or acceleration) phase occur while adverse pressure exerted the deceleration phase occur. Hajimirzaie et al. (2014) examined the mean wake and turbulent flow field around sphere placed structures by using experimental methods which are Particle Image Velocimetry (PIV) and Thermal Anemometry methods, they investigated at Reynolds number of 17800 . They examined the flow surrounding the spherical obstacle by PIV techniques, and anemometry measurements used to characterize the instability in the weak. They identified a spectral peak in the wake at $\mathrm{St}=0.203$, simply close to base plane. Dantas and de Barros (2013) obtained the hydrodynamic forces generated on an AUV considering the combined effects of the control surface deflection and the angle of attack using CFD software based on the Reynolds-averaged Navier-Stokes formulations. They attained better results by using $\mathrm{k}-\omega$ SST model compared to another models. These numerical results showed that fully turbulent models could approximate hydrodynamic forces with a good level of accuracy with little errors in streamline because major part of flow was laminar. Maruyama at al. (2012) investigated wind loads acting on buildings located in turbulent boundary layer by using LES method with ANSYS. On the other hand, in wind tunnel experiment, Particle Image Velocimetry (PIV) technology has been modified to catch high frequency turbulent fluctuations. The results have shown that the turbulent boundary layer acceptably produced in LES with high resolution in near wall region as well as DNS though the experimental results of PIV were coarser than numerical with LES and DNS. Jimenez (2007) has investigated the flow characteristics around submarine and torpedo-like geometry by using PIV flow visualization technique at high Reynolds number. He found that with the increasing of Reynolds number $1.1 \times 106$ to $2.5 \times 107$, the stagnation point in the wake region moved from $3 \mathrm{D}$ to $15 \mathrm{D}$, respectively. Beheshti et al. (2009) studied on the flow physics around an airship in a water tunnel. They measured the drag on a small scaled model of the airship to identify a laminar-to-turbulent boundary layer transition. It was observed that the body with appendages resulted in 30\% higher drag compared to the bare hull. Mansoorzadeh and Javanmard (2014) have investigated the free surface effect on drag and lift coefficient of an AUV that obtained numerically and experimentally. They concluded that the drag coefficient was the function of the Reynolds number and submergence ratio of AUV. Fureby et al. (2016) have examined a generic conventional submarine at yaw angle of $10^{\circ}$. PIV system integrated to a wind tunnel which has been used for the experimental part of the study while LES turbulence model has been utilized to obtain numerical results. The aim of this study is to examine the flow structures around a torpedo-like geometry placed in a boundary layer flow, experimentally.

\section{Materials and Methods}

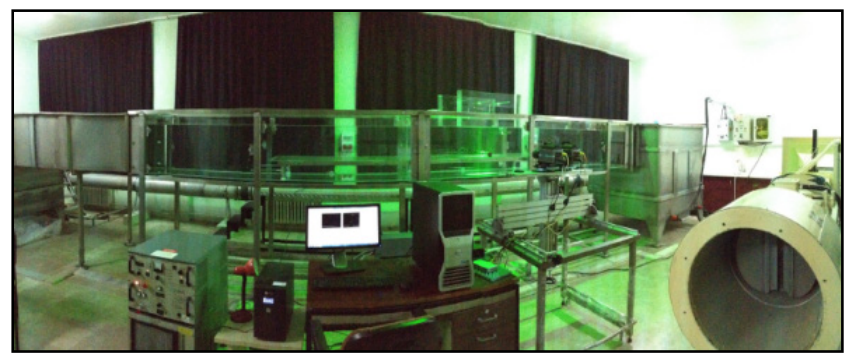

Figure 1. Experimental setup

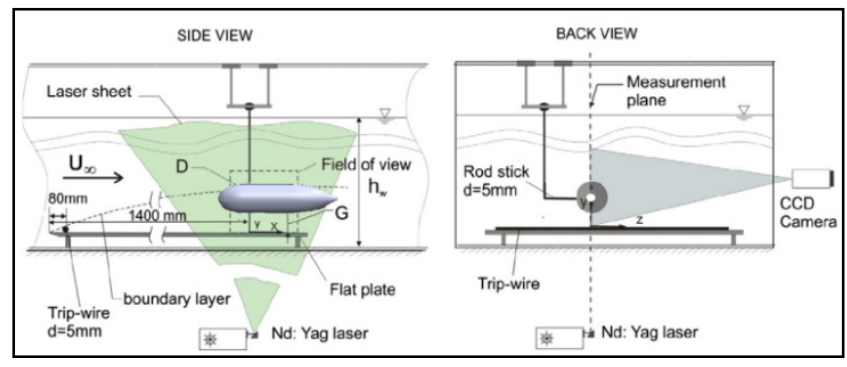

Figure 1. Schematic view of the experimental view of PIV system, laser illumination for a torpedo like geometry located in a boundary layer

Experiments were performed with the Particle Image Velocimetry (PIV) system. Large-scale open loop water channel with a rectangular cross-section $6000 \mathrm{~mm} \times 770$ $\mathrm{mm} \times 600 \mathrm{~mm}$ was used in the facilities of Advanced Technology Research and Application Center of Selcuk University at Konya/Turkey. The water channel was indicated in figure 1 . The walls of the test-section were made of $15 \mathrm{~mm}$ thick glass plates to facilitate laser transmission and flow visualization. The water height was kept constant as $\mathrm{hw}=470 \mathrm{~mm}$ in all cases and the space between the bottom point of the geometry and flat plate surface differs from 0 to $60 \mathrm{~mm}$ and normalized with the diameter as G/D. The orientation of the torpedo-like geometry in the experimental setup has been shown in figure 2 . To have fully developed turbulent boundary layer, the torpedo-like geometry was mounted about $1400 \mathrm{~mm}$ 
from leading edge of the flat plate. It has been found that the developed hydrodynamic boundary layer thickness was $\delta=60.91 \mathrm{~mm}$ at $\mathrm{Re}=20000$ and $\delta=40.45$ at $\mathrm{Re}=40000$ for the water channel without the torpedo-like geometry. The boundary layer thickness has been calculated from the $\mathrm{u}$-velocity profile and using free stream velocity.

Reynolds numbers were calculated by, $\operatorname{Re}=\mathrm{U}_{\infty} \mathrm{L} / \mathrm{v}$; based on the characteristic length of the geometry. Here, $v$ is the kinematic viscosity and $\mathrm{L}$ is the characteristic length of the geometry. $U_{\infty}$ is the free-stream velocity in the range of $100-200 \mathrm{~mm} / \mathrm{s}$. The geometry has been made of acrylic glass with the $2.5 \mathrm{~mm}$ thickness so that the laser light easily passes through the geometry. The inner section of the geometry has been filled with water to minimize the laser light deflection. Nd: YAG laser has been utilized to generate a laser sheet which was perpendicular to the axis of the geometry and it has passed through the geometry with 15 pulses per second. A Complementary Metal Oxide Semiconductor (CMOS) camera with a resolution of 1632 x 1200 pixels was used to record the images. The densities of the particles and water were close enough and the suspended seeding particles with a diameter of $10 \mu \mathrm{m}$ in the flow were silver coated hollow glass spheres. Dynamic Studio software employing the adaptive correlation algorithm including proper filters were used for computing the raw displacement vector field. An interrogation window of $32 \times 32$ pixels in the image was selected and converted to approximately $1,41 \times 1,41 \mathrm{~mm} 2$ grid size consisting of $7474(101 \times 74)$ velocity vectors. During the interrogation process, an overlap of $\% 50$ has been employed in order to satisfy the Nyquist criterion. Patterns of instantaneous particle images with 1024 images consisting of a continuous series were taken at the rate of $15 \mathrm{~Hz}$ to calculate the time-averaged patterns of the flow structure.

Power law expression and experimental results have been compared and the power law index $\mathrm{u} / \mathrm{U}_{\infty}=(\mathrm{y} / \delta) 1 / \mathrm{n}$ for $\mathrm{n}=5$ for both $\mathrm{Re}=20000$ and $\mathrm{Re}=40000$ is in $\operatorname{good}$ agreement as indicated in Fig. 3, respectively.

\section{Results and Discussion}

Flow characteristics around a torpedo-like geometry have been investigated using PIV technique and time-averaged vector fields $\langle\mathrm{V}\rangle$, Reynolds stress correlations $\left\langle\mathrm{u}^{\prime} v^{\prime} / \mathrm{U}_{\infty}{ }^{2}\right\rangle$, time-averaged streamwise velocity components $\left\langle\mathrm{u}^{*}>\right.$ and streamline topologies $\langle\Psi\rangle$ for different gap ratios of $0 \leq \mathrm{G} / \mathrm{D} \leq 1.5$ at $\mathrm{Re}=20000$ and 40000. Normalizing the dimensions by dividing the amounts by diameter of torpedo-like $\mathrm{x} / \mathrm{D}, \mathrm{y} / \mathrm{D}$, and $\mathrm{G} / \mathrm{D}$ has been done and streamwise velocity components have been normalized by free-stream velocity as $<^{*}=\mathrm{u} / \mathrm{U}_{\infty}>$. The maximum and minimum values have been given with a legend bar for the contours in each figure and divided with 15 levels. The positive layers of flow patterns have been displayed with continuous line contours as red background color, while the negative layers have been indicated with dashed line contours as blue background color. With the assistance of PIV method, the recirculating and separated flows in the near wake region of torpedo-like geometry have been observed under the effect of a boundary layer.
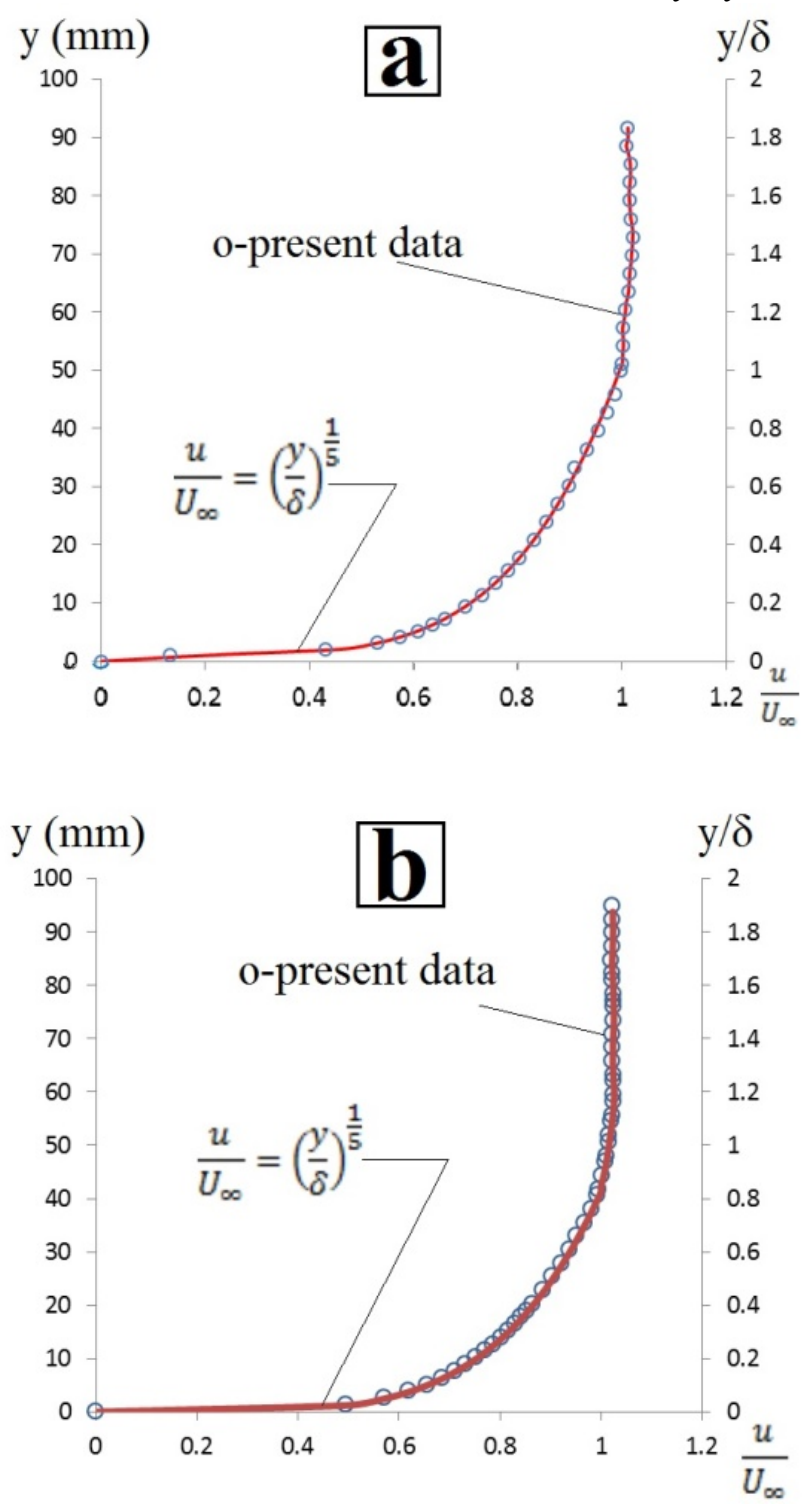

Figure 2. The development of turbulent boundary layer by the velocity distribution with the influence of tripwire and sharp-edged flat plate at $\mathrm{Re}=20000$ (a) and at $\mathrm{Re}=40000$ (b) when compared between experimental and power-law results $\mathrm{u} / \mathrm{U}_{\infty}=(\mathrm{y} / \delta) 1 / \mathrm{n}$ and here the index $\mathrm{n}=5$

In Fig. 4 and Fig. 5, time-averaged vector fields $<\mathrm{V}>$ have been presented at $\mathrm{Re}=20000$ and $\mathrm{Re}=40000$, respectively. Rotational flow has been seen in the bottom section of trailing edge for the torpedo-like geometry due to the interaction between the flat plate and torpedo-like geometry. Jet-like flow occurs by increasing the gap ratio to $\mathrm{G} / \mathrm{D}=0.25$ and the separation point was at $\mathrm{x}=4.5 \mathrm{D}$. Furthermore, reverse velocity vectors have been obtained in the wake region and positive vector values occur in the bottom section of the trailing edge because of jet-like flow and boundary layer effect in the first column (I) of Fig. 5 and 6 . In case of $\mathrm{G} / \mathrm{D}=1.5$, flow structure around the 
torpedo-like geometry approached to the uniform flow conditions as observed.
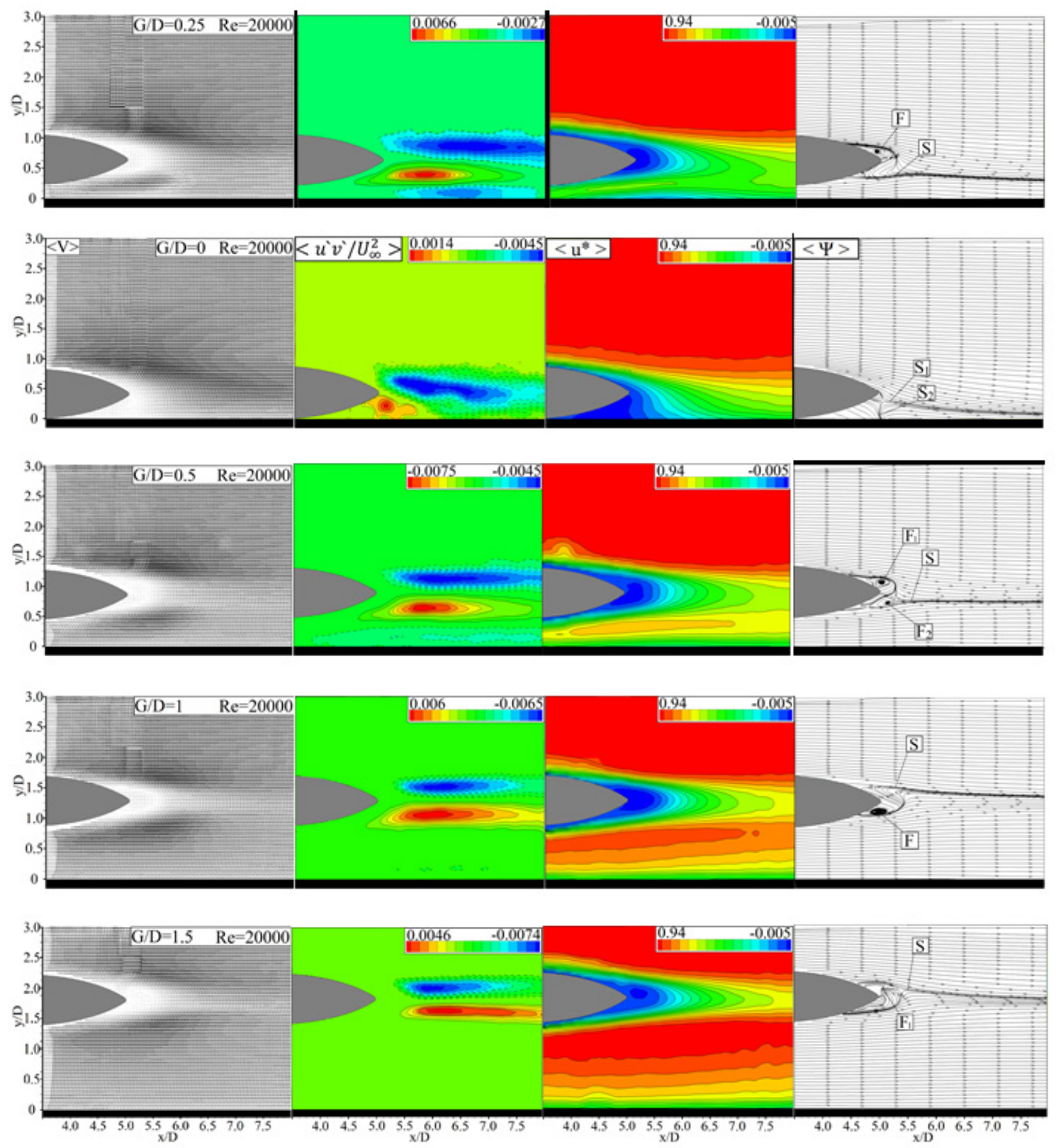

Figure 4. Comparison of velocity vector field $\langle V\rangle$ (column I), Reynolds stress correlations $\left\langle\mathrm{u}^{\prime} v^{\prime} / \mathrm{U}_{\infty}{ }^{2}\right\rangle$ (column II), normalized time-averaged velocity components in $\mathrm{x}$ direction $\left\langle\mathrm{u}^{*}>\right.$ (column III), variations of the time averaged streamline topology $<\psi>$ (column IV) around the torpedo for $0 \leq \mathrm{G} / \mathrm{D} \leq 1.5$ at $\operatorname{Re}=$ 20000 

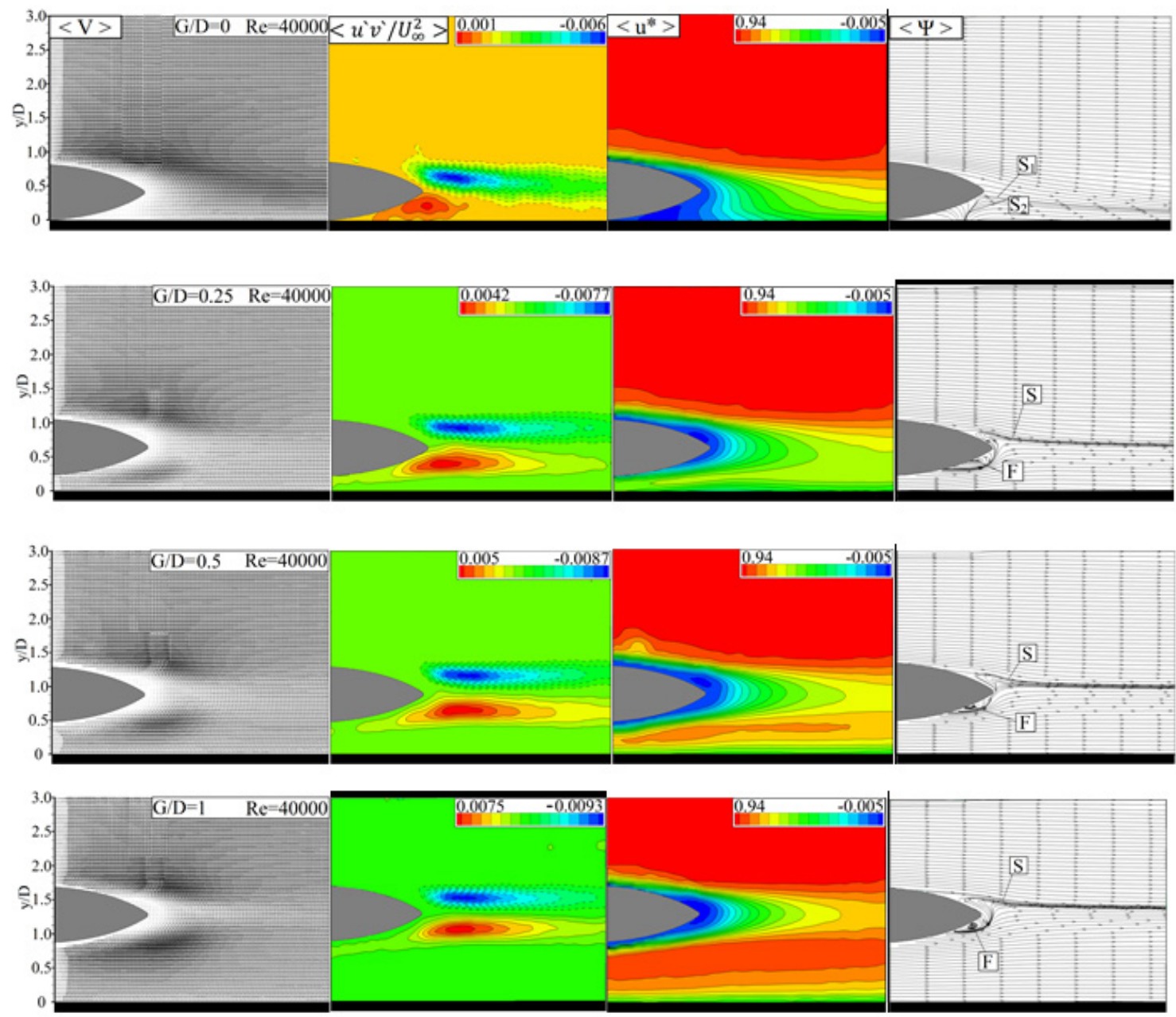

Figure 5. Comparison of velocity vector field $<\mathrm{V}>$ (column I), Reynolds stress correlations $<\mathrm{u}^{\prime} \mathrm{v}^{\prime} / \mathrm{U} \infty 2>$ (column II), normalized time-averaged velocity components in $\mathrm{x}$ direction $\left\langle\mathrm{u}^{*}>\right.$ (column III), variations of the time averaged streamline topology $<\psi>$ (column IV) around the torpedo for 0 $\leq \mathrm{G} / \mathrm{D} \leq 1.5$ at $\mathrm{Re}=40000$

The effects of $G / D$ ratios on the wake region of the torpedo-like geometry and the boundary layer were discussed, in terms of Reynolds stress correlations $\left\langle u^{\prime} v^{\prime} /\right.$ $\mathrm{U}_{\infty}{ }^{2}>$ and shown in Fig. 4 and 5. Unsymmetrical peak values of negative and positive Reynolds stress correlations are generated in the wake region at downstream of the torpedo-like geometry. The boundary layer affected on Reynolds stress correlations $\left\langle\mathrm{u}^{\prime} v^{\prime} / \mathrm{U}_{\infty}{ }^{2}\right\rangle$ with unsymmetrical distribution when the geometry mounted near the flat plate. For $G / D=0$, only negative Reynolds stress correlations can be demonstrated on the top sheer layer and showed with dashed lines. At $\mathrm{G} / \mathrm{D}=0$, torpedo-like geometry contacted with flat plate, therefore, the clusters and minimum values of Reynolds stress correlations located at the top section of the torpedo-like geometry. Furthermore, with increasing the gap ratio, the effect of jet-like flow at the bottom on the positive values was bigger than the upper negative values showed in Figs. 4 and 5. Moreover, the cluster of positive Reynolds stress correlations values began to get larger in the downstream of the torpedo-like geometry as the gap ratio between the plate and torpedo-like geometry increased to $\mathrm{G} / \mathrm{D}=0.25$ for $\mathrm{Re}=20000$ and 40000 . Jet-like flows through the gap resulted in this condition. Reynolds stress correlations $\left\langle\mathrm{u}^{\prime} v^{\prime} / \mathrm{U}_{\infty}{ }^{2}\right\rangle$ at $\mathrm{G} / \mathrm{D}=0.25$, the positive region begins to occur and consists of two negative values one of them is over the flat plate due to the effect boundary layer and the jet-like flow through this gap and the other at the top of torpedo-like geometry. In case of $\mathrm{G} / \mathrm{D}=0.25$, the peak value has been obtained because the downstream of jet-like flow deployed up through the trailing edge of the torpedo-like geometry. The separation of downstream flow at the trailing edge of the torpedo-like geometry resulted in large-scale correlations of Reynolds stress correlations $\left\langle u^{\prime} v^{\prime} / U_{\infty}{ }^{2}>\right.$ in the wake region. Reynolds stress correlations represented the comparative of momentum transfer for the two Reynolds numbers analyses. As examined from Figs. 4 and 5 , the disappearance of small scaled values of Reynolds stress correlations at a small distance from trailing edge of the torpedo-like geometry was about $\mathrm{x} / \mathrm{D}=7.3$ (i.e. $0.7 \mathrm{D}$ from the base of the geometry) and it was earlier at $R e=40000$ than $R e=20000$.

Streamwise velocity components $<\mathrm{u}^{*}>$ have been obtained for different gap ratios and shown in column (III) of Fig. 4 and Fig. 5 at $R e=20000$ and $R e=40000$, respectively. Negative values of streamwise velocity 
components have been attained around the lower region of the symmetry axis due to the interaction of the model and the flat plate at $\mathrm{G} / \mathrm{D}=0$. In this region, the rotational flow has been obtained. In cases of $\mathrm{G} / \mathrm{D}=0.25$ and $\mathrm{G} / \mathrm{D}=0.5$, the boundary layer kept its effect on the model but the cluster with negative values went up and approached to the symmetry axis. However, the distributions of streamwise velocity components nearly approached to uniform flow conditions at $\mathrm{G} / \mathrm{D}=1$ and uniform flow conditions have been approximately attained at $\mathrm{G} / \mathrm{D}=1.5$ as free-stream velocity values observed in the vicinity of the lower part of the torpedo-like geometry. For the gap ratio of $\mathrm{G} / \mathrm{D}=0.25$, the effect of jet-like flow in wake region observed. The symmetrical flow structure of the torpedo-like geometry was seen after the disappearance of the jet-like flow in the Fig. 5 and 6. Another deduction from the results is that flow separation has been observed about $\mathrm{x} / \mathrm{D}=4.5$ and its influence on wake region has been seen with negative values of streamwise velocity components. However, flow separation differed due to the boundary layer effect when compared the upper and lower regions of the torpedo-like geometry. For this reason, flow separation points were different for lower gap ratios because of the boundary layer on the flat plate. When Reynolds number increased to $\mathrm{Re}=40000$, wake region became closer to the torpedo-like geometry. Moreover, the boundary layer affected the wake region less than $\mathrm{Re}=20000$ as seen in Fig 3(b).

As some reflection on the torpedo-like geometry caused by the manufacturing defect, the presence of symmetrical flow structure was not seen obviously for time-averaged streamline patterns $\langle\Psi\rangle$ of the torpedo-like geometry in Figs. 4 and 5. Over here, F1 and F2 show the foci of the rotational flow field in a limit cycle, S1 and S2 are saddle

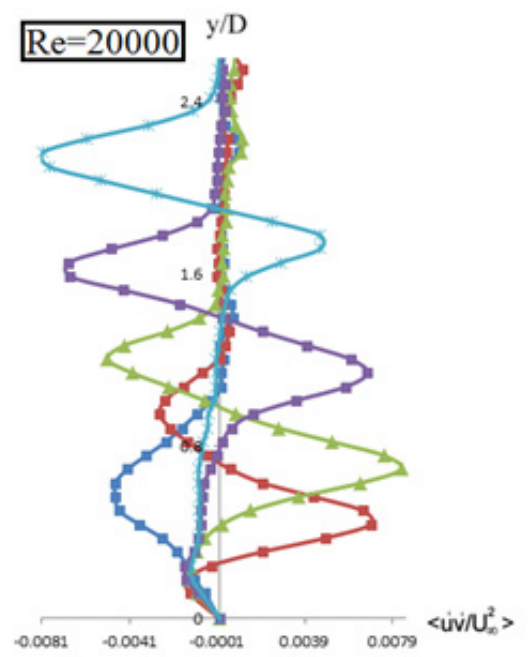

point and they represent free stagnation points in the flow field. At $\mathrm{G} / \mathrm{D}=0$, there were only two saddle points in the region for all cases while no available foci points due to the boundary layer. Streamline topology was raised from the bottom of the torpedo-like geometry toward the trailing edge and entangled by shear layer then separated from the bottom section of the torpedo-like geometry. While the gap ratio rose to $\mathrm{G} / \mathrm{D}=0.25$, a focus point has been obtained for each case but one of them was over the symmetry axis for $\mathrm{Re}=20000$ and the other was below at $\mathrm{Re}=40000$. On the other hand, as jet-like flow began the shedding shear layer not to just happen over the trailing edge but it also occurred in the bottom section of the trailing edge. At $\mathrm{Re}=20000$ in case of $\mathrm{G} / \mathrm{D}=0.5$, there were two foci points and only one saddle point obtained. However, streamline topologies of the torpedo-like geometry for $\mathrm{G} / \mathrm{D}=1.0$ and $\mathrm{G} / \mathrm{D}=1.5$ were well-ordered.

As seen from Fig. 6, the Reynolds stress correlations $\left\langle u^{\prime} v^{\prime} / U_{\infty}^{2}\right\rangle$ distributions were obtained in the vertical line from the second column of Figs. 4 and 5 and at the $x / D=5.7$ from the trailing edge of the torpedo-like geometry at $\mathrm{Re}=20000$ and 40000 . The gap ratio between the flat plate and the bottom point of the torpedo-like geometry is validated between $0 \mathrm{~mm}$ and $60 \mathrm{~mm}$ for both Reynolds numbers of $R e=20000$ and $R e=40000$. At $G / D=0$, only negative Reynolds stress correlations $\left\langle u^{\prime} v^{\prime} / U_{\infty}{ }^{2}\right\rangle$ were demonstrated in the wake region of the torpedo-like geometry. As the gap ratio increased to $G / D=0.25$ and $\mathrm{G} / \mathrm{D}=0.5$, the negative values of the Reynolds distributions $\left\langle u^{\prime} v^{\prime} / U_{\infty}{ }^{2}\right\rangle$ occurred at the upper of downstream, the positive value occurred in the bottom and became symmetric from the tails axis. The boundary effect is gradually disappear and symmetric shape of distribution occurs at $\mathrm{G} / \mathrm{D}=1.0$ and 1.5 for both $\mathrm{Re}=20000$ and 40000 .

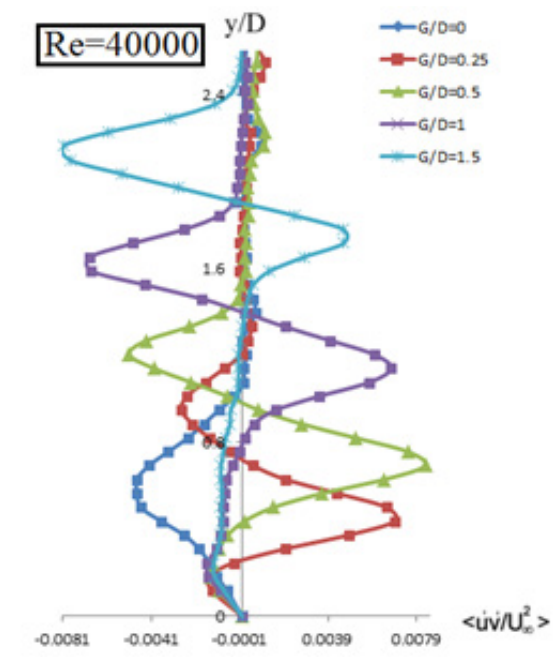

Figure 6. Variation of Reynolds stress correlations $<\mathrm{u}^{\prime} v^{\prime} / \mathrm{U} \infty 2>$ along the vertical line displayed in the second column of Figures 5 and 6 at $\mathrm{x} / \mathrm{D}=5.7$ away from the tail of the torpedo for $0 \leq \mathrm{G} / \mathrm{D} \leq 1.5$ at $\mathrm{Re}=20000$ and 40000 


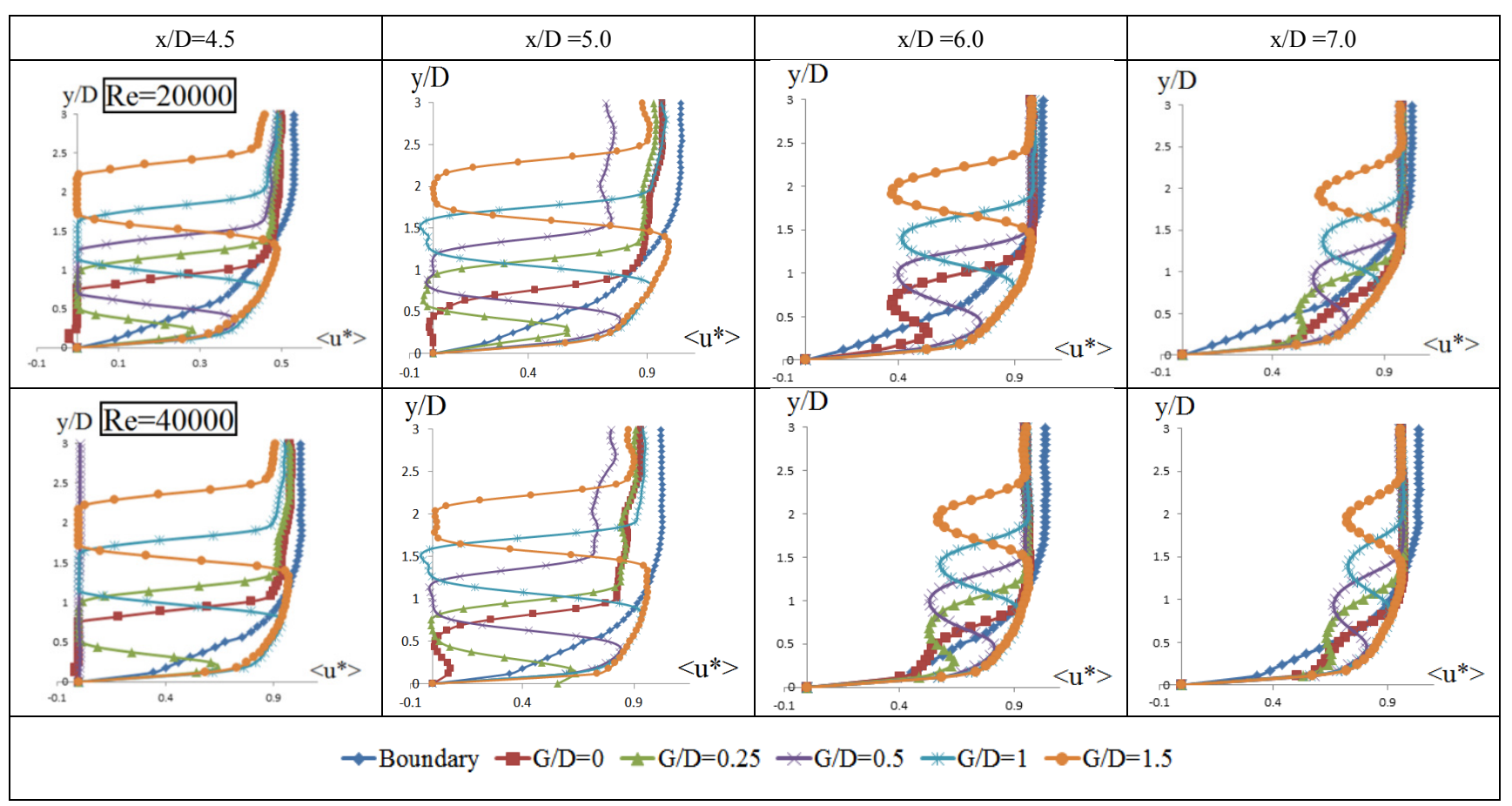

Figure 7. Distributions of time averaged streamwise velocity component $\left\langle\mathrm{u}^{*}>\right.$ along the vertical lines designated with $\mathrm{x} / \mathrm{D}=4.5,5.5,6.0$ and 7.0 in the third column images of Figures 4 and 5 downstream of the torpedo at gap ratio values of $0 \leq \mathrm{G} / \mathrm{D} \leq 1.5$, right column for $\mathrm{Re}=20000$ and left column for $\mathrm{Re}=40000$. Continuous line represents the boundary layer velocity profile over a flat plate in the wake region of torpedo

Fig. 7 shows the time averaged streamwise velocity distributions $\left\langle\mathrm{u}^{*}\right\rangle$ along a vertical line. They were obtained at different values of torpedo wake region $\mathrm{x} / \mathrm{D}=$ 4.5, 5.0,6.0 and 7.0 showed in the third column of Fig .5 and 6 at the gap ratios $0 \leq \mathrm{G} / \mathrm{D} \leq 1.5$ and for $\mathrm{Re}=20000$ and 40000 . Here, the blue line that increased gradually refers to the boundary layer over a flat plate as discussed before in Figs. 3 and 4 . The negative velocity components $\left\langle u^{*}\right\rangle$ was demonstrated at gap ratio $\mathrm{G} / \mathrm{D}=0$ for both Reynolds number 20000 and 40000 , in addition the negative $\left\langle\mathrm{u}^{*}>\right.$ value was occurred at $\mathrm{G} / \mathrm{D}=0.25$ and $\mathrm{Re}=20000$ but it wasn't seen for $\mathrm{Re}=40000$ at the same gap ratio $\mathrm{G} / \mathrm{D}=0.25$. At $\mathrm{Re}=20000$ value for all gap ratios the uniform flow condition was occurred at height ratio $y / D=2.5$, and the same condition was occurred at $\mathrm{y} / \mathrm{D}=2.3$ for $\mathrm{Re}=40000$. Different velocity distributions was demonstrated at length ratio $\mathrm{x} / \mathrm{D}=4.5$ for all gap ratios both $\mathrm{Re}=20000$ and 40000 at height ratio $y / D=2.5$, however the velocity distributions $\left\langle u^{*}>\right.$ for all gap ratios at $\mathrm{x} / \mathrm{D}=5,6$ and 7 , and height ratio $y / D=2.5$. The reason was the flow streamwise at different gap ratios for length ratio $x / D=4.5$ influenced from the boundary layer that generated at torpedo's surface.

\section{Conclusions}

In this paper, the effects of boundary layer on the flow characteristics of a torpedo-like geometry and the correlation investigation of these mechanisms all were done experimentally. All $\mathrm{x}$-direction velocity $\left\langle\mathrm{u}^{*}>\right.$ results has been obtained under the same scale, the normalized minimum and maximum values $(-0.005$ and 0.94$)$ for both
$\mathrm{Re}=20000$ and 40000.

Some of the obtained points and investigation results are presented as follow:

- The effect of gap ratio, between the torpedo-like geometry and flat plate on wake region is started at $\mathrm{G} / \mathrm{D}=0.25$ and increased gradually until $\mathrm{G} / \mathrm{D}=0.5$, furthermore the effect of gap ratio decreased at $\mathrm{G} / \mathrm{D}=1.0$ which the symmetric structure has been occurred at $\mathrm{G} / \mathrm{D}=1.5$.

- For the velocity distributions $<\mathrm{u}^{*}>$ obtained with influence of boundary layer on the torpedo-like geometry has been disappeared at height ratio $\mathrm{y} / \mathrm{D}=2.5$ at $\mathrm{Re}=20000$, and at $\mathrm{y} / \mathrm{D}=2.3$ for $\mathrm{Re}=40000$.

- The back flow at wake region of the torpedo-like geometry for the gap ratios $\mathrm{G} / \mathrm{D}=0.25$ and 0.5 , the separated flow from the bottom of the torpedo-like geometry tail and the gap flow was affected on the flow structure.

- The non-uniform velocity profile of the boundary layer have been resulted in various shapes of separated shear layers from the tail of torpedo-like geometry and have resulted in changing the patterns of negative and positive values of $\mathrm{x}$-directions velocity over the flat plate.

\section{Acknowledgements}

The authors would like to acknowledge the funding of Scientific and Technological Research Council of Turkey 
(TUBITAK) under Contract No. 214M318.

\section{REFERENCES}

[1] H. Zhao, X. Liu, D. Li, A. Wei, K. Luo, J. Fan, "Vortex dynamics of a sphere wake in proximity to a wall", International Journal of Multiphase Flow, vol. 79, pp. 88-106,Mar. 2016.

[2] M. Ozgoren, A. Okbaz, S. Dogan, B. Sahin, H. Akilli, "Investigation of flow characteristics around a sphere placed in a boundary layer over a flat plate", Exp. Thermal Fluid Sci., vol. 44, pp. 62-74, Jan. 2013.

[3] N. Cheng, "Power-law index for velocity profiles in open channel flows", Adv. Water. Res., vol. 30, pp. 1775-1784, Aug. 2007.

[4] A. Ozalp, I. Dincer, "Hydrodynamic-thermal boundary layer development and mass transfer characteristics of a circular cylinder in confined flow", Int. Journal of Theermal. Sci., vol. 49, pp. 1799-1812, Sep. 2010.

[5] M. Ozgoren, E. Pinar, B. Sahin, H. Akilli, "Comparison of flow structures in the downstream region of a cylinder and sphere", Int. Journal of Heat and Fluid Flow, vol. 32, pp. 1138-1146, Dec. 2011.

[6] C. Lin, S. Yu, W. Wong, G. Tzeng, M. Kao, P. Yeh, R. Raikar, J. Yang, C. Tsai, "Velocity characteristics in boundary layer flow caused by solitary wave travelling over horizontal bottom", Exp. Thermal Fluid Sci., vol. 76, pp.
238-252, Sep. 2016.

[7] S. Hajimirzaie, A. Tsakiris, J. Buchholz, A. Papanicolaou," Flow characteristics around a wall-mounted spherical obstacle in a thin boundary layer", Exp. Fluids, vol. 55: pp. 1762, March 2014.

[8] J. L. D. Dantas and E. A. de Barros, "Numerical analysis of control surface effects on AUV manoeuvrability", Applied Ocean Research, vol. 42, pp. 168-181, Aug. 2013.

[9] Y. Maruyama, T. Tamura, Y. Okuda, M. Ogashi, "LES of turbulent boundary layer for inflow generation using stereo PIV measurement data", J.Wind Eng. Ind. Aerodyn, vol. 104-106, pp. 309-388, Jul. 2012.

[10] J.M. Jimenez, "High Reynolds number flows about bodies of revolution", $\mathrm{PhD}$ Thesis, Mechanical and Aerospace Engineering, Princeton University, vol. 68-03, Jan. 2007.

[11] B. H. Beheshti, F. Wittmer and R. S. Abhari, "Flow visualization study of an airship model using a water towing tank", Aerospace Science and Technology, vol. 13, pp. 450458, Dec. 2009.

[12] Sh. Mansoorzadeh, E. Javanmard, “An investigation of free surface effects on drag and lift coefficients of an autonomous underwater vehicle (AUV) using computational and experimental fluid dynamics methods", Journal of Fluids and Structures, vol.51, pp. 161-171, Nov. 2014.

[13] C. Fureby, B. Anderson., D. Clarke, L. Erm, S. Henbest, M. Giacobello, D. Jones, M. Nguyen, M. Johansson, M. Jones, C. Kumar, S. K. Lee, P. Manovski, D. Norrison, K. Petterson, G. Seil, B. Woodyatt and S. Zhu, "Experimental and numerical study of a generic conventional submarine at $10^{\circ}$ yaw", Ocean Engineering, vol. 116, pp. 1-20, Apr. 2016. 